\title{
FOLIA
}

Amazónica

Revista del Instituto de Investigaciones

de la Amazonía Peruana

\section{EVALUACION DEL COMPORTAMIENTO PRODUCTIVO DE Cyclanthera pedata EN UN CULTIVO ACUAPÓNICO Y CONVENCIONAL, YARINACOCHA}

\author{
Elmo TANKAMASH UGKUCH ${ }^{1}$, Nadia Masaya PANDURO TENAZOA ${ }^{1}$, \\ José Gerardo SÁNCHEZ CHOY SÁNCHEZ ${ }^{1}$, Jessy Isabel VARGAS \\ FLORES ${ }^{1}$, Ricardo Julián OLIVA PAREDES ${ }^{1}$, Pablo Pedro VILLEGAS \\ PANDURO $^{2}$
}

1. Universidad Nacional Intercultural de la Amazonía

2. Universidad Nacional de Ucayali. ppvillegasunu@gmail.com

\section{RESUMEN}

Se busca evaluar el comportamiento productivo de Cyclanthera pedata en un cultivo acuapónico y convencional en el Distrito de Yarinacocha, Región Ucayali. El sistema acuapónico estuvo sustentado por la crianza de Piaractus brachypomus "Paco", acondicionados en tanques de crianza, con camas de graba (con un sistema de riego proveniente de los tanques del cultivo de peces, con 15 minutos de riego y 45 minutos de descanso) y el sistema convencional estuvo constituido por camellones en el suelo, mullido y mezclado con gallinaza descompuesta. Se realizó el almacigado de las plántulas hasta que obtengan 16 cm de altura, momento en el cual se trasplantó tanto a las camas de graba del sistema acuapónico como en los camellones del sistema convencional, se realizó el manejo agronómico correspondiente para ambos sistemas de cultivo. Se aplicó un Diseño Completamente al Azar (DCA), con 2 tratamientos y 3 repeticiones; determinándose que, el cultivo de la caigua en un sistema acuapónico presentó mayores valores para el peso de fruto, número de frutos por hectárea y rendimiento por hectárea; mientras que el sistema convencional, fue mejor en cuanto a la longitud de fruto; en cuanto al diámetro de fruto no se encontraron diferencias significativas entre ambos sistemas de cultivo.

PALABRAS CLAVE: sistema acuapónico, sistema convencional, caigua, rendimiento. 


\title{
EVALUATION OF PRODUCTIVE BEHAVIOR OF Cyclanthera pedata IN A ACUAPÓNIC AND CONVENTIONAL CULTURE, YARINACOCHA
}

\begin{abstract}
The aim of research was evaluate productive behavior of Cyclanthera pedata in an aquaponic and conventional crop in the District of Yarinacocha, at Ucayali Region. The aquaponic system was supported by breeding of Piaractus brachypomus "Paco", conditioned in breeding tanks, with a log bed (with an irrigation system from fish culture tanks, with 15 minutes of watering and 45 minutes of rest). ) and the conventional system was constituted by ridges in the ground, soft and mixed with decomposed poultry litter. Storage of seedlings was done until they reached $16 \mathrm{~cm}$ in height, then were transplanted both to the recording beds of the aquaponic system and in the ridges of the conventional system, the corresponding agronomic management was carried out for both systems culture. A Completely Random Design (DCA) was applied, with 2 treatments and 3 repetitions; determining that, caigua culture in an aquaponic system presented higher values for fruit weight, number of fruits per hectare and yield per hectare; while the conventional system was better in terms of fruit length; Regarding fruit diameter, no significant differences were found between the two culture systems.
\end{abstract}

KEYWORDS: Aquaponic system, conventional system, caigua, yield, survival percentage. 


\section{INTRODUCCIÓN}

El sistema acuapónico constituye una integración entre un cultivo de peces y uno hidropónico de plantas. En este sistema, los desechos metabólicos generados por los peces y los restos de alimento, son utilizados por los vegetales y transformados en materia orgánica vegetal. Gracias a esto, los sistemas acuapónicos trabajan sobre dos puntos de gran interés en producción, rentabilidad y tratamiento de desechos (Jiménez, 2013), utilizando una cantidad comparativamente pequeña de agua, y produciendo muy pocos desechos (Rahman, 2005; Wilson, 2006), pudiendo mejorar su rendimiento bajando los costos de alimentación de los peces, utilizando plantas que se pueden cultivar en condiciones limpias, como las lentejas de agua (Lemma minor), y similares, que pueden ser utilizadas por peces omnívoros como la tilapia (Oreochromisniloticus), las carpas (Cyprinus carpio), y probablemente la cachama blanca (Piaractus brachypomus) (Acero, 2002; Acero, 2005; Gómez y Acero, 2002; Ortiz, 2003; Range y Range, 2006).

Los sistemas acuapónicos son un medio eficaz para reducir y aprovechar los residuos que normalmente son vertidos al ambiente, debido a quelas plantas recuperan un porcentaje sustancial de los nutrientes disueltos, reduciendo los costos de operación por acarreo de agua, generando vegetales con un valor agregado porque pueden ser considerados como "productos orgánicos", ya que excluye el uso de químicos como plaguicidas y fertilizantes (García et al., 2014).

A menudo estos sistemas son caros de construir y de operar, sin embargo, mediante la incorporación de un cultivo secundario de plantas, que recibe la mayoría de los nutrientes necesarios sin costo adicional, el beneficio del sistema de cultivo puede mejorar, ya que las plantas utilizadas en el sistema acuapónico purifican el agua de cultivo (García et al., 2014).
En un sistema acuapónico, las plantas se benefician del desecho de los peces (consumo de nitrógeno) y a la vez purifican el agua las cuales son aprovechas por los peces. El agua, por estar en constante movimiento mejora las condiciones de oxígeno, importante para los peces y los peces generan amonio las cuales son transformadas por las bacterias en nitrato la cual es aprovecha por las plantas, disminuyendo los niveles de toxicidad para los peces (García et al., 2014).

Domesticada en los Andes, la caigua fue representada ya desde épocas tempranas en las sociedades prehispánicas, como los Mochicas hacia el 200 d.c. (Larco, 2001, citado por Chuquin, 2009). Actualmente, no solamente es conocida en la Amazonía del Perú y Bolivia, sino que también en otras zonas de América del Sur y América Central, así como algunas partes del hemisferio norte tropical (Chuquin, 2009).

Según Ugás et al. (2000), la cosecha se efectúa cuando los frutos están maduros, color verde intenso y uniforme, turgentes, de alrededor de 20 cm de largo, que no hayan empezado a amarillear. Así mismo, que el rango o promedio nacional están entre las 400000 a 500000 unidades, teniendo de esta manera un rendimiento promedio de $7371 \mathrm{~kg} / \mathrm{ha}$.

El objetivo del estudio fue evaluar el comportamiento productivo de Cyclanthera pedata "Caihua" en un cultivo acuapónico en comparación con un cultivo convencional en el distrito de Yarinacocha.

\section{MATERIALES Y METODOS}

La investigación se realizó en las instalaciones del Sistema Acuapónico, ubicado en la carretera San José $0,5 \mathrm{~km}$, distrito de Yarinacocha, provincia de Coronel Portillo, Región Ucayali, situándose en las coordenadas geográficas: Latitud: $8{ }^{\circ} 21^{\prime} 47^{\prime \prime}$ Longitud: $74^{\circ} 34^{\prime} 00^{\prime \prime}$ altitud: 154 metros. 
Elanálisis de calidad de aguas se realizó durante el proceso de investigación, determinándose que el $\mathrm{NH}_{3}$ presento niveles promedio de $0,08 \mathrm{mg} / \mathrm{L}$, y nitrito, la media máxima fue de $0,45 \mathrm{mg} / \mathrm{L}$. Según Casas (2008) los niveles de tolerancia de los peces al $\mathrm{NH}_{3}$ está ubicado entre 0,6 y 2,0 ppm $\mathrm{y}$ nitrito pueden ser estresantes para el pez, a concentraciones tan bajas como 0,1 ppm. Pilco (2015) determino niveles similares en $\mathrm{NH}_{3} \mathrm{mg} / \mathrm{L}$ $0,081 \pm 0,004 \mathrm{mg} / \mathrm{L}$ y nitritos de 0,33 $\pm 0,175$ $\mathrm{mg} / \mathrm{L}$. Los niveles de $\mathrm{NO}_{3}$ presentaron un nivel máximo promedio de $55 \mathrm{mg} / \mathrm{L}$ y un nivel mínimo de $25 \mathrm{mg} / \mathrm{L}$. Estos niveles indican que se está realizando un buen proceso de nitrificación. Por otro lado, los niveles de $\mathrm{pH}$ estuvieron cercanos al neutro. Los valores de $\mathrm{NO}_{3}(\mathrm{mg} / \mathrm{L})$ son cercanos a lo determinado por Pilco (2015) en un sistema acuapónico, de 25 a $60 \mathrm{mg} / \mathrm{L}$.

La cama de cultivo tuvo una dimensión de 7 metros de largo y 1,20 metros de ancho teniendo un total de $8,4 \mathrm{~m}^{2}$, construidas con material noble, y con un sustrato constituido por graba de $0,5 \mathrm{~cm}$ de diámetro, homogéneamente distribuidas. El agua proveniente de los tanques de crianza de peces, se distribuyó mediante tuberías de manera uniforme en todas las camas, con la ayuda de una bomba periférica de $2 \mathrm{HP}$, para lo cual se programó el timer para bombear 15 minutos y apagarse 45 minutos consecutivamente.

En los tanques de cultivo de peces, se sembraron alevinos de Piaractus brachypomus "Paco" de $15 \mathrm{~g} / \mathrm{pez}$, a una densidad de 50 alevinos $/ \mathrm{m}^{3}$, los cuales fueron los primeros organismos en entrar al sistema, para el enriquecimiento continuo de las camas de cultivo con sus excretas y así favorecer el desarrollo de las bacterias nitrificadoras (Nitrosomonas sp. y Nitrobactar sp.) (Colagrosso, 2014), creany 120 días de instalados. do las condiciones óptimas para la siembra de las plantas.

Para el sistema convencional, se procedió a seleccionar un área de cultivo cercano a las instalaciones del sistema acuapónico; para luego preparan una cama elevada de $7 \mathrm{~m}$ x 1,2 m y 10 $\mathrm{cm}$ de alto. Sobre la cama elevada, se procedió a aplicar $50 \mathrm{~kg}$ de abono orgánico (gallinaza descompuesta), se homogenizo el abono con el suelo, para realizar el transplante.

Se almacigaron semillas de caigua de 20 a 30 días, lográndose plántulas de $16 \mathrm{~cm}$ de alto en promedio, momento en el cual se transplantaron a las camas de cultivo definitivo, tanto en el sistema acuapónico y en el sistema convencional.

Se sembró un total de 210 plantas de caigua por sistema de cultivo, a un distanciamiento de $0,20 \mathrm{~m} \times 0,20 \mathrm{~m}$, para un total de $8,4 \mathrm{~m}^{2}$, tanto para el sistema acuapónico, como para el sistema convencional.

Los datos obtenidos de la investigación fueron analizados en un diseño completo al azar, con un nivel de confianza de 95\%, asimismo, se utilizó una prueba de promedios de Tukey.

\section{RESULTADOS Y DISCUSIONES}

\section{A. LONGITUD Y DIÁMETRO DE FRUTO}

La tabla 1, muestra la prueba de promedios de Tukey, para la longitud y diámetro de fruto de caigua en la primera y segunda evaluación.

Tabla 1. Longitud y diámetro de fruto en la primera y segunda evaluación a los 90

\begin{tabular}{lcccc}
\hline \multirow{2}{*}{ Tratamientos } & \multicolumn{2}{c}{ Longitud de fruto $(\mathrm{cm})$} & \multicolumn{2}{c}{ Diámetro de fruto $(\mathrm{cm})$} \\
\cline { 2 - 5 } & 90 días & 120 días & 90 días & 120 días \\
\hline Sistema convencional & $6,82 \mathrm{a}$ & $13,06 \mathrm{a}$ & $1,33 \mathrm{~b}$ & $4,59 \mathrm{a}$ \\
Sistema acuapónico & $2,64 \mathrm{~b}$ & $12,28 \mathrm{~b}$ & $3,56 \mathrm{a}$ & $4,69 \mathrm{a}$
\end{tabular}

Letras iguales no presentan diferencias significativas. Tukey $p \leq 0,05$ 
Para la longitud de frutos a los 90 días y 120 días de instalados, el sistema convencional presento mayor longitud de fruto con respecto al sistema acuapónico. Para el diámetro de frutos a los 90 días, los frutos de caigua cultivados en el sistema acuapónico presentaron mayor diámetro de fruto en comparación con el sistema convencional y a los 120 días, no se observaron diferencias significativas entre los frutos cultivados en ambos sistemas.

Al respecto, Schwember et al. (2014), indica que el fruto de la caigua es una baya solitaria que mide de 10 a 20 centímetros de largo y 4 a $8 \mathrm{~cm}$ de ancho, el cual coincide con la longitud y diámetro de fruto encontrado en los dos sistemas de cultivo, los cuales se encuentran entre un rango de longitud de 12,28 a 13,06 $\mathrm{cm}$ y de 4,59 a 4,69 cm de diámetro.

\section{B. PESO DE FRUTOS, NÚMERO DE FRUTOS POR HECTÁREA Y RENDIMIENTO}

La tabla 2, muestra la prueba de promedios de Tukey, para el peso de frutos, número de frutos por hectárea y rendimiento de caigua.

Tabla 2. Peso de frutos, número de frutos/ha y rendimiento de caigua.

\begin{tabular}{lcccc}
\hline Tratamientos & $\begin{array}{c}\text { Peso de fruto } \\
(\mathrm{g})\end{array}$ & No de frutos/ha & $\begin{array}{c}\text { Rendimiento } \\
\text { (ton/ha) }\end{array}$ \\
\hline Sistema convencional & $51,86 \mathrm{~b}$ & $144048 \mathrm{~b}$ & $7,467 \mathrm{~b}$ \\
Sistema acuapónico & $85,46 \mathrm{a}$ & $210714 \mathrm{a}$ & $18,048 \mathrm{a}$ \\
\hline
\end{tabular}

Letras iguales no presentan diferencias significativas. Tukey $p \leq 0,05$ frutos por hectárea superiores a los obtenidos en el presente trabajo de investigación. Sin embargo, Schwember et al. (2014), indica que quienes cultivan caigua en la Zona Norte de Chile, los rendimientos corresponderían a 6,5 ton/ha aproximadamente, mientras que existen reportes que en Perú se alcanzarían las 7,3 ton/ ha. Asimismo, Ugáz et al. (2000), indican que el rango o promedio nacional están entre las 400 000 a 500000 unidades, teniendo de esta manera un rendimiento promedio de $7371 \mathrm{~kg} / \mathrm{ha}$, el cual coincide con los resultados obtenidos en el sistema de cultivo convencional, con 7,467 ton/ ha, pero que es superado por los resultados de rendimiento obtenidos en el sistema de cultivo acuapónico, el cual llegó a un rendimiento de 18,048 ton/ha.

Comparando la eficiencia de los sistemas acuapónicoyelrendimiento dediferentesespecies cultivadas, Mentha piperita, cuyo componente medicinales son el mentol, la mentona, alfa y beta pineno, entre otros (Shylaja y Peter, 2004), es un cultivo altamente rentable (Ramírez et al., 2008), la cual es considerada como "ideal" para la acuaponía (Cuthbert, 2008). Asimismo, el orégano, sembrado a una densidad de 40000 plantas/ha, y 3 cortes por año, se pueden lograr rendimientos de 15 ton/ha en fresco, la cual, se presenta como un cultivo promisorio para ser
Para el peso de fruto, número de frutos/ha $\mathrm{y}$ rendimiento (ton/ha), se observa que el sistema acuapónico presentó mejores promedios en comparación con el sistema convencional.

UNA La Molina (2000) indica que a un distanciamiento de 4,0 m entre surco, 0,5 - 0,8 m entre golpe y a 2 plantas por golpe, se obtiene un rendimiento de 400000 - 500000 frutos/ ha, siendo estos rendimiento de número de explotado en sistemas acuapónicos (Ramírez et al., 2008). Otra especie de mucha importancia económica es la lechuga, siendo una de las plantas que más se han utilizado en sistemas acuapónicos, con bastante éxito si se mantienen adecuadamente los niveles de luz, $\mathrm{pH}$, potasio y hierro requeridos por estas plantas (Rakocy, 2006). Siendo las plantas con fruto, los más difíciles de obtener, como es el caso del tomate, 
pero con la adición adecuada de quelatos de hierro y un buen control de plagas, se puede tener buena cosecha (Rakocy, 2006).

\section{CONCLUSIONES}

Para el peso de fruto, número de frutos por hectárea y rendimiento por hectárea, el cultivo de la caigua en un sistema acuapónico presentó mayores promedios; mientras que para la longitud de fruto, el sistema convencional presento mayores promedios; en cuanto al diámetro de fruto no se encontraron diferencias significativas entre ambos sistemas de cultivo.

\section{AGRADECIMIENTO}

Al Instituto Superior Pedagógico Bilingüe de Yarinacocha, y a la ONG INMED Andes (Servicio Médico Internacional), por proveer las instalaciones del Sistema Acuapónico para el desarrollo de la investigación.

\section{REFERENCIAS BIBLIOGRAFICAS}

Acero, L.E. 2002. Guía para el cultivo y aprovechamiento del Chachafruto o Balú Erythrina edulis Triana ex Micheli.

Acero, L.E. 2005. Guía para el cultivo y aprovechamiento del árbol del pan Artocarpus altilis (Park.) Fosberg. Convenio Andrés Bello, Serie Ciencia y Tecnología. Bogotá, Colombia

Casas, D. 2008. Sistema de recirculación de agua para la cría intensiva de cachama blanca (Piaractus brachypomus). Tesis de pre-grado, Universidad Centroccidental, Cabudare-Venezuela. 97 pp. Disponible en: http://es.scribd.com/doc/253604808/CriaIntensiva-de-Cachamas\#scribd.
Colagrosso, A. 2014. Instalación y manejo de sistemas de cultivo acuapónicos a pequeña escala. Recovered: http://es.calameo.com/ read/00536860803513b156f19

Chuquín, F. M. 2009. Caracterización morfológica de la variabilidad genética de achogcha (Cyclanthera pedata) en el Cantón Cotacachi. Tesis de pre grado, Universidad Técnica del Norte, Facultad de Ingeniería en Ciencias Agropecuarias y Ambientales. Ibarra, Ecuador. Cuthberg, K. 2008. A South African system. Backyard Aquaponics, Número 2: 5-9. Segundo trimestre. 7- De la Ossa J, Botero LM. 2003. Guía para la cría, manejo y aprovechamiento sostenible de algunas especies animales promisorias y otras domésticas. Convenio Andrés Bello, Serie Ciencia y Tecnología. Bogotá, Colombia

García, U.; M.; León, C.; Hernández, F.; Chávez, R. 2005. Evaluación de un sistema experimental de acuaponía. Avances en investigación agropecuaria. 9 (1) 1-5. Recovered of http:// redalyc.org/articulo.oa?id=83709105

Gómez, M.E.; Acero, L.E. 2002. Guía para el cultivo y aprovechamiento del Bore Alocasia macrorrhiza (Linneo) Schott. Convenio Andrés Bello. Serie Ciencia y Tecnología. Bogotá, Colombia

Jiménez, A. 2013. «Acuaponía: Herramienta educativa para el aprendizaje transversal de las ciencias». Revista Ciencia y Desarrollo, 16(2) 83-90. doi: http://dx.doi.org/10.21503/cyd. v16i2.1113

Nelson, R.L. 2007. Acuaponía. Nelson/Pade Multimedia. Montillo, WI. USA.

Ortiz, C.D. 2003. Guía para alimentación animal y elaboración de concentrados. Convenio Andrés Bello, Serie Ciencia y Tecnología. Bogotá Colombia.

Pilco, J. 2015. Comportamiento productivo de dos densidades de siembra de Piaractus brachypomus "Paco" en un sistema acuapónico 
superintensivo, en el IESPPB, 2015. Tesis de pre-grado, Universidad Nacional Intercultural de la Amazonia, Facultad de Ingeniería y Ciencias Ambientales. Pucallpa-Perú.

Racocy, J. 2006. Questions and Answers. Aquaponics Journal. Número 41:8-11, Segundo trimestre.

Rahman, M.F. 2005. As I see it. Futuristic environment-friendly technologies for growing plants. Aquaponics Journal. Número 39:44-45. Cuarto trimestre.

Range, P.; Range, B. 2006. Homemade and alternative fish feed. Aquaponics Journal. Número 40:18-20, primer trimestre.

Ramírez, D.; Sabogal, D.; Jiménez, P.; HurtadoGiraldo, H. 2008. La acuaponía: una alternativa orientada al desarrollo sostenible. Revista Facultad de Ciencias Básicas. ISSN 1900-4699, Volumen 4, Número 1, Páginas 32-51, 2008.
Schwember, A.; Segura, P. \& Contreras, S. 2014. Caigua, cucurbitácea nativa con potencial hortícola. Agronomía y Forestal, 50:1517. Recovered of http://agronomía.uc.cl/ component/com_sobipro/ltemid,232/ pid,1607/sid,1615/

Shylaja, M.R.; Peter, K.V. 2004. The functional role of herbal species. In: Handbook of herbs and species. Vol. 2. Peter K.V. (ed). Woohead Publishing in Food Science and Technology. England.

Ugáz, R.; Siura, S.; Delgado de la Flor, F.; Casas, A.; Toledo, J. 2000. Datos básicos de hortalizas: Caigua. Recovered of http://lamolina.edu.pe/ hortalizas/Datosbasicos.html

Van Gorder, S.D. 2000. Small scale aquaculture. The Alternative Aquaculture Association. Breinigsville, PA, USA.

Wilson, G. 2006. Aquaponics miserly water use. Aquaponics Journal. Número 40:14-17.

Recibido: 19 de octubre de 2018 Aceptado para publicación: 12 de diciembre de 2018 